\title{
Integração conceptual, formação de conceitos e aprendizado
}

\author{
Ana Flávia Lopes Magela Gerhardt \\ Universidade Federal do Rio de Janeiro, Programa de Pós-Graduação em Letras Vernáculas
}

\section{Introdução}

Em muitos países, boa parte das pesquisas sobre os problemas educacionais relacionados à cognição humana tem seguido postulações piagetianas e vygotskyanas. Em virtude dos trabalhos de Jean Piaget não discutirem os efeitos do aprendizado no desenvolvimento cognitivo, os estudos interessados especificamente nas relações entre cognição e escolarização têm assumido as ideias de Lev Vygotsky como orientação teórico-epistemológica.

Ao discutir o aprendizado, Vygotsky, principalmente em Pensamento e linguagem, advoga o papel estruturador da aquisição de conceitos no desenvolvimento cognitivo, visto que cada conceito aprendido pode afetar e transformar estruturas cognitivas já estabelecidas. Para isso, Vygotsky admite como premissas que a mente se estrutura em domínios específicos e que o aprendizado provoca uma expansão de propriedades e conteúdos de um domínio para o outro.

Em relação ao que Vygotsky estabeleceu como linha mestra em seu trabalho, suas premissas são importantes porque sustentarão a sua hipótese teórica principal, que lança as bases marxistas de formulação do desenvolvimento cognitivo como internalização e transformação de conceitos por meio do intercâmbio com artefatos culturais. Nesse contexto, a escola é um ambiente fundamental, porque oferece instrumentos para que os alunos possam aprender, já que para o pensador russo, o desenvolvimento cognitivo da pessoa relaciona-se à inserção num grupo cultural e resulta da interação com os instrumentos e as semioses desse grupo.

Em Pensamento e linguagem, o pesquisador russo, além de propor a internalização de estruturas externas como base da construção do conhecimento, também se dedicou a investigar a ontogênese da formação dos conceitos, mostrando que a criança passa por duas fases de desenvolvimento antes de estar apta a formá-los: primeiro, a capacidade de amontoar objetos da sua experiência, interpretando-os sem critério; segundo, a capacidade de compor um pensamento por complexos, em que as relações estabelecidas entre os objetos já existem, mas são factuais, e não lógicas. No estágio de formação de conceitos verdadeiros, 
a criança deve ser capaz de sistematizar, unificando organizadamente os conceitos da sua experiência, bem como de abstrair, isolar em sua mente esses elementos, num processo de análise-síntese. É de se notar que, em sua hipótese, Vygotsky se antecipa ao modelo de processamento interativo estudado pela psicolinguística décadas depois, e ainda é inspirador de muitas propostas da ciência da cognição relacionadas ao assunto.

Ao vencer essas fases, a criança está apta a alcançar as chamadas funções psíquicas superiores: dedução, compreensão das noções de mundo, interpretação da causalidade física, domínio das formas lógicas de pensamento, domínio da lógica abstrata etc. Tais funções psicológicas superiores se evidenciam em construções sócio-históricas materializadas nas relações sociointeracionais, que alcançam o seu ápice de refinamento no contexto que o autor russo instituiu como zona de desenvolvimento proximal.

Nas suas pesquisas, o pensador russo optou por investigar crianças de mais de 2 anos de idade que, em princípio, já teriam adquirido as capacidades cognitivas básicas para proceder às fases por ele descritas e à internalização (Tomasello, 1996). Provavelmente por isso, a ausência de estudos que investigassem quais são essas capacidades cognitivas básicas inerentes aos seres humanos preocupou Vygotsky, que mencionou a necessidade de explicar em que termos elas se constituem na mente das pessoas. Isso nos leva a reconhecer que, no seu trabalho, muito embora não haja ações de pesquisa especificamente nesse sentido, ocorre uma reflexão acerca das bases processuais-cognitivas do aprendizado e do desenvolvimento cognitivo.

Mesmo com essa observação de Vygotsky, muitos dos estudos que ao longo dos anos beberam na fonte dos seus achados têm caminhado guiados pelos seus resultados e não pela sua crítica: trabalham para estabelecer algumas evidências mais específicas de que a pessoa aprendeu e desenvolveu-se cognitivamente, norteados pela identificação das funções psíquicas superiores postas pelo autor russo. Dessa forma, muitos trabalhos que discutem o assunto buscam premissas, parâmetros de observação e evidências para identi- ficar os atributos de uma pessoa que obteve sucesso no processo de construção de conceitos, mas não discutem de fato a forma que esse aprendizado acontece como processo cognitivo em si e o que significa o momento do aprender como experiência interna à pessoa, quando um novo conceito, como representação mental, é criado.

Este artigo pretende discutir duas das conclusões a que chegaram esses trabalhos, a fim de definir sobre quais bases eles se fundamentam e se eles pretendem ou logram realizar o que Vygotsky achou necessário para entender o que acontece na mente das pessoas no momento em que elas assimilam um conceito. Após uma avaliação crítica dessa compilação, pretende-se delinear o que a ciência cognitiva contemporânea pode oferecer em termos de abordagem processual do aprendizado, com base na noção de integração conceptual (Fauconnier \& Turner, 2002), ou, mais especificamente, no double-scope blending, relacionado às funções superiores gerais da cognição humana (Fauconnier \& Turner, 2009). Propõe-se essa reflexão com base nas possibilidades conceituais com que atualmente as ciências da cognição acenam para uma percepção cada vez mais aguda do que precisa ser estimulado na pessoa para favorecer-lhe o aprendizado.

É necessário salientar de pronto que não é objetivo deste trabalho estabelecer compatibilidades teórico-epistemológicas entre $\mathrm{o}$ arcabouço conceitual vygotskyano e a ciência cognitiva contemporânea, não modularista e não autonomista. Essa tarefa alcança uma dimensão infinitamente maior, mais adequada a um projeto integrado de pesquisa do que propriamente a um artigo. $\mathrm{O}$ que se pretende aqui é poder pensar, dentro de uma visão atualizada sobre a cognição, em uma questão específica posta pelo pensador russo e na possibilidade de a ciência cognitiva trazer instrumentos que permitam falar sobre essa questão, num diálogo que referenda a legitimidade, ainda nos dias de hoje, de um problema apontado décadas atrás.

Essa possibilidade de diálogo interdisciplinar não é inédita: já está registrada em trabalhos de pesquisadores em psicologia cognitiva alinhados a pressuposições cognitivistas básicas de observação da mente 
e do ser humano (Tomasello, 1996; Sinha \& Jensen de López, 2000). Da mesma forma, não é inédito um pensar sobre internalização e ciência cognitiva em moldes contemporâneos: ele também se encontra em Susswein, Bibok e Carpendale (2007), mas, diferentemente de nós, esses autores não se propuseram a definir um processo cognitivo específico no diálogo com a percepção vygotskyana sobre aprendizado.

O texto se organiza nas seguintes etapas: apresentam-se duas perspectivas de aprendizado que são caras aos trabalhos de base vygotskyana - a articulação entre conceitos e o descolamento da realidade imediata - e a análise dos tratamentos a eles conferidos. Propõe-se uma visão do aprendizado como uma double-scope blending e os prováveis efeitos da adoção dessa visão no universo escolar.

\section{Perspectivas de investigação do aprendizado}

A investigação da literatura sobre aprendizado e desenvolvimento cognitivo permite definir dois grandes tópicos gerais: articulação entre conceitos e descolamento da realidade imediata. Não raro esses dois fatores são discutidos juntos.

A relação entre aprendizado, desenvolvimento cognitivo, articulação de conceitos e consequente descolamento da realidade imediata goza de tradição nos estudos em psicologia da aprendizagem e tem sido levada em conta em diversas pesquisas voltadas à problemática educacional.

Em trabalhos como Olson \& Astington (1990), Oliveira (1999) e Olson (2002), a articulação de conceitos e o descolamento da realidade imediata estão inalienavelmente atrelados: neles, as noções de aprendizado e desenvolvimento cognitivo focalizam a capacidade que uma pessoa tem de organizar e articular os conceitos assimilados na realidade social a que pertence. Nesse aspecto, então, uma cognição supostamente mais desenvolvida diria respeito a conceitos pertencentes a universos não aderidos à realidade imediata (Oliveira, 1999, com base nos trabalhos de Vygotsky e Luria) e organizados de forma integrada. O contrário, isto é, a desarticulação de conceitos, não proporciona à pessoa meios de descolamento, já que assim não é possível a ela relacionar universos de experiência.

\section{Articulação de conceitos}

É possível inserir a articulação de conceitos em um processo maior, ou seja, sua inserção em estruturas mais complexas, por conta da hipótese vygotskyana de que o letramento é a apropriação de um instrumento (para Emilia Ferreiro, uma técnica) que transforma as chamadas funções de raciocínio superior. De modo genérico, os instrumentos materiais assimilados pelo grupo social se transformam, via internalização, em instrumentos simbólicos, objetos de aprendizado. Nesse processo, atrelam-se, de um lado, a qualidade de lectoescrita, portanto, de raciocínio; de outro, o fato de uma pessoa pertencer a um dado grupo social. Tal fato também é uma fonte de relação estreita entre escolarização, letramento e desenvolvimento cognitivo.

A questão relevante e central nos trabalhos acerca da cognição como articulação de conceitos é definir exatamente o que se toma por conceito. Passaremos a essa discussão a seguir.

Muito se tem discutido sobre como os conceitos se nos afiguram. As especulações normalmente optam por contrapor, de um lado, a visão clássica, referente às taxonomias e às listas dos chamados traços necessários e suficientes, e, de outro lado, as concepções mais atuais, referentes à forma como vemos o mundo e como isso determina a organização conceitual (Lakoff, 1987; Kunda, 1999).

No caso da conceituação clássica, postulam-se organizações objetivas dos conceitos, segundo as quais eles permaneceriam apartados do ser humano, independentemente da forma como as pessoas os manipulam. A objetividade dessa visão favorece a caracterização dos conceitos como cotidianos, científicos, empíricos, concretos, abstratos etc. Essa tipologia leva naturalmente ao estabelecimento de conceitos sofisticados, sistemáticos, formatados, ao lado de conceitos simples, cotidianos, assistemáticos, não formatados. Os conceitos científicos teriam lugar na escola, nos centros de pesquisa e outros espaços de construção e 
disseminação de conhecimento, e se colocariam imunes a interferências do cotidiano; por esses motivos, seriam mais sistematizados. Os conceitos cotidianos, por sua vez, teriam lugar no ambiente doméstico, lúdico, em que não há necessidade de sistematização descritiva e explicativa, e sua aquisição não seria finalidade última (Wells, 1994; Oliveira, 1999).

Vygotsky, em Pensamento e Linguagem, buscou uma caracterização que pudesse diferenciar conceitos cotidianos (que Piaget denominava espontâneos) e escolares (não espontâneos), muito embora tenha assumido que eles estejam relacionados e se influenciem mutuamente, o que o leva a supor que haja um mesmo processo para a formação de ambos - e, no que diz respeito a este artigo, motiva a busca de uma invariante processual na formação de conceitos e no aprendizado. Com base em suas pesquisas, e de acordo com a sua proposta epistemológica, Vygotsky concluiu que se tratava de elementos de naturezas diversas, porque formados em ambientes diferentes, por diferentes motivos e com diferentes condições de acessibilidade. Embora, ao contrário de Piaget, Vygotsky tenha assumido a importância do estudo dos conceitos cotidianos, eles foram em princípio tomados como inferiores aos escolares, porque seriam menos abstratos, menos generalizados e menos sistematizados, isto é, menos articulados entre si.

É interessante notar que a ideia de sistematização posta por Vygotsky em Pensamento e Linguagem diz respeito à organização dos conceitos, um sendo entendido relativamente ao outro. $\mathrm{O}$ entendimento de que os conceitos veiculados na escola (ou seja, conceitos científicos) são sistematizados, leva a criança a reconfigurar os seus conceitos cotidianos, sistematizando-os também - quer dizer, aprendizados novos são capazes de modificar estruturas já aprendidas. Da proposta de Vygotsky podemos inferir que a diferença qualitativa entre os conceitos cotidianos e escolares não é inerente aos conceitos, mas sim às suas condições de produção. Assim, os conceitos cotidianos estão aptos a serem sistematizados da mesma forma, pela via da escolarização.

Entretanto, o senso comum valoriza os conceitos científico-escolares por outros motivos. Na diferen- ciação entre eles e os conceitos cotidianos, concorrem determinações externas, históricas: sua valorização por parte das elites socioculturais da sociedade ocidental; sua documentação bibliográfica (o que acaba sendo causa e consequência da sua valorização diante dos outros conceitos); sua transmissão metodologizada, formalizada e institucionalizada; e a existência de uma metalinguagem agregada (Wells, 1994). Esse estado de coisas pode motivar a ideia de que a escola, que surge como ambiente ideal para a transmissão dos conceitos científicos, produziria saberes de melhor qualidade, cujo aprendizado acarretaria mais inteligência e mais sucesso escolar.

Para os autores que questionam a suposta superioridade dos conceitos científicos, eles na verdade fariam parte de teorias que os organizam e definem. Teorias, nesse caso, seriam organizações de conceitos que evidentemente só podem ser vistos em conjunto, estruturados relativamente às teorias de que fazem parte. Essa visão parece captar melhor a complexidade da organização conceitual da mente humana e traria, em relação à abordagem clássica, a vantagem de tratar dos conceitos de forma orgânica, estruturada, e não isoladamente (Oliveira, 1999, p. 82). Para Gilles Deleuze e Félix Guattari (1992, p. 31), o plano da inter-relação entre conceitos recebe a oportuna denominação de plano de pensabilidade, no qual essa articulação se daria não apenas na ontologia de cada conceito, mas também em sua história e em seu devir.

$\mathrm{O}$ que de interessante emerge dessa postulação é que ela permite um tratamento homogêneo dos conceitos, rompendo a distinção entre cotidianos e científicos, empíricos e teóricos etc., e assim põe em xeque a base objetivista da conceituação clássica: os conceitos estão sujeitos a mudanças mediante a interferência humana em interação com todos os objetos cognoscíveis, especialmente em contextos de interação social. Assim, não haveria diferença qualitativa entre as informações dadas na escola e os outros conceitos presentes na vida cotidiana - em ambos os casos, lidamos com artefatos de base cognitivo-perceptual, mas também cultural (Bergen \& Feldman, 2006).

E, de fato, hoje se pode dizer que a oportunidade de adquirir os conceitos chamados científicos depende 
da participação da pessoa em atividades em que esse tipo de conceito está presente em ações conjuntas (Wells, 1994; Sinha, 1999a), assim como ocorre em qualquer situação de aprendizado. Em outras palavras, a aquisição dos conceitos científicos se dá em ambientes de letramento, num sentido lato (Street, 1984; Kleiman, 1998).

Neste artigo, tomamos como premissa a homogeneidade entre os conceitos e o mesmo valor para tudo aquilo que o ser humano aprender e em qualquer lugar. Essa definição desconsidera a hipótese de que a pessoa escolarizada, que teve contato com conceitos científicos, seria mais desenvolvida cognitivamente do que a pessoa que não frequentou os bancos escolares, já que aqui estamos inclinados a reconhecer que a mente humana funciona da mesma forma no contato com todo tipo de conceito, informação e conhecimento, o que lhe permite articulá-los eficientemente.

Com base nisso, não se considerará também a ideia de que os conceitos escolarizados e científicos seriam mais sistematizados que os cotidianos, já que a atribuição de sistematizar (e ser sistemático) não está no conceito, mas sim na pessoa, que os formata, organizando-os em sua mente e articulando-os a padrões de conhecimento já assimilados e constituídos: esquemas imagéticos (Johnson, 1987), modelos cognitivos idealizados (Lakoff, 1987), linguagem, cenas conceptuais (Fillmore, 1977), molduras comunicativas (Goffman, 1986). São bases de conhecimento cuja identificação permite reconhecer o saber formal ensinado nas escolas como tendo o mesmo valor que os saberes com os quais a pessoa tem contato fora da escola, já que, para o aprendizado de ambos, a mente terá de realizar as mesmas operações de checagem, formatação e acomodação, a ponto de se dizer que, sem sistematizar, a mente não formaliza, não aprende. A diferença entre os dois está apenas no fato de que, na escola, estar-se-á lidando com informações a ela pertinentes. Tal fato abre espaço para a suposição de que o ambiente em si não é suficiente para formar conceitos, mas concorre para estabelecer as suas condições de validação (Sinha, 1999a). Essa hipótese será explorada neste artigo.
Um estudo que buscou descrever e teorizar sobre a formação e articulação de conceitos foi o de Gentner \& Loewenstein (2002), trabalho cuja motivação, também presente neste artigo, é a ausência de pesquisas sobre como os conceitos se formam e se relacionam, muito embora a sofisticação das capacidades cognitivas humanas - categorização, perspectivação, diferenciação e projeção interdominial, enquadre etc. - esteja sendo descrita com apuro cada vez maior. Os achados investigados por autores apontam para a definição de mecanismos inatos de processamento de conceitos para formar outros novos, mas também atestam que a literatura não é generosa na proposta de como esses conceitos se criam.

Diante desse cenário, os autores buscam uma explicação processual para o aprendizado, assumindo de imediato que os conceitos, muito embora não se produzam do nada, podem desenvolver um caráter absolutamente autônomo em relação àqueles dos quais provieram, e nesse sentido Gentner \& Loewenstein pertinentemente consideram os conceitos existentes como substratos para a construção cognitiva.

Para essa tarefa, os autores assumem modelos domain-specific de organização cognitiva para configurar o que denominam relational thought, não apenas responsável pela estruturação dos conteúdos mas também pela reflexão teórica da pessoa (no sentido posto por Oliveira, 1999) sobre eles. Essa ideia os leva a compreender o relational thought como algo que se faz em dois planos ${ }^{1}$ de conhecimento: de um lado, o plano do conhecimento sobre as coisas; de outro, o plano do conhecimento das formas de comparar as coisas, checando semelhanças e diferenças entre elas - ou seja, realizando analogias a fim de inseri-las em categorias. Nesse sentido, segundo os autores, com base na categorização chega-se à padronização necessária à formação e depreensão dos conceitos. A linguagem seria a representação estrutural dessa atividade e um dos seus componentes desencadeadores.

${ }^{1}$ As descrições da conceptualização como ocorrendo em dois planos são recorrentes na literatura em psicologia cognitiva (Olson \& Astington, 1990; Tomasello \& Rakoczy, 2003). Sobre o tema ver também Sinha (1999a) e Sinha \& Jensen de López (2000). 
$\mathrm{Na}$ proposta dos autores acerca do relational thought, tido como a base da articulação e consequente formação de novos conceitos, a comparação é tratada pelos autores como um processo de alinhamento estrutural geral, porque leva, com base no nível local, correlações a ser articuladas a padrões estruturais gerais de conceitos. Para os autores, os elementos em comparação podem ser de qualquer natureza, o que permite incluir aí a equivalência valorativa, também assumida por nós, entre os conteúdos ministrados na escola e os saberes trazidos pelos alunos em sua vida fora dela. Os saberes de toda natureza, a tomar pelo processo descrito, seriam alinhados, ajustados e organizados em categorias, havendo a possibilidade de formação de novas categorias com base nesse alinhamento mútuo, que promoverá a compreensão relacional porque permite formar categorias das semelhanças e diferenças entre os seus elementos.

Segundo Gentner \& Loewenstein (2002, p. 97), a comparação pode promover aquisição de conhecimento das seguintes formas: definindo padrões (como abstrações esquemáticas); projetando inferências de um elemento de comparação a outro; alterando representações para melhorar a correlação entre os elementos, no sentido de que eles, apenas por serem comparados, já se tornam diferentes, criando novos domínios com base nos existentes, e com isso confirmando teses caras às abordagens vygotskyanas de uma mente estruturada em domínios específicos.

De fato, o alinhamento de elementos em categorias é a base da compreensão humana das coisas por excelência, e a ideia de comparar, checar semelhanças e diferenças, e daí formar categorias, é uma das ações humanas mais importantes, o que já foi atestado por autores emblemáticos da psicologia e da linguística cognitivas (Rosch, 1978; Lakoff, 1987; Taylor, 1987). Gentner \& Loewenstein, com sua proposta, vinculam-se aos que postulam a natureza processual e projecional da cognição humana, baseada principalmente na capacidade de articular diferentes domínios, e não os vê de forma encapsulada (Karmiloff-Smith, 1992; Fauconnier \& Turner, 2002; Tomasello, 1999; Sinha, 1999b).
Entretanto, embora os autores não advoguem pelo encapsulamento dos universos de experiência, não tratam os elementos a ser alinhados para a formação das categorias de acordo com os universos de experiência em que se produzem e se validam. Isso, numa visão de cognição situada (Tomasello, 1999, 2003; Sinha, 1999a; Clark, 2004), precisa ser levado em conta em função do fato de que a categorização, como agrupamento de objetos/entidades por quaisquer características/funções julgadas similares, não diz respeito apenas aos objetos em si, mas à cena (Fillmore, 1977), à moldura sociocultural (Lakoff, 1987) e, no desenvolvimento humano, ao tipo de informação que os adultos oferecem às crianças à medida que elas acomodam os conceitos em categorias (Resnick 1994; Clark, 2004; Tomasello, 2003).

Além disso, a nossa capacidade de categorizar emerge naturalmente da nossa habilidade de construir múltiplas representações de experiência, as quais proporcionam, além das categorias, outras propriedades ligadas ao desenvolvimento cognitivo - identificação, referenciação, tipificação, memória etc.

Outra questão a ser notada é que a visualização do processo de formação do relational thought de Gentner \& Loewenstein (2002) conta com apenas dois elementos, precisamente aqueles que são alinhados/ comparados para a formação de um terceiro, que é justamente o conceito inserido em uma categoria, mas que fica fora do processo, mesmo sendo o seu resultado. Provavelmente por isso os autores não explicam o que é o novo conceito aprendido, o que o constitui e como ele se insere no processo que descrevem. À página 95, os autores apresentam o processo de projeção estrutural: primeiro, o alinhamento, depois, a projeção das inferências; mas não há menção ao resultado do processo.

Nesse sentido, tem-se que os autores postulam (o que não se encontra em seu texto como afirmação explícita, mas pode ser inferido com base nos seus objetivos) que categorizar é criar novos conceitos, novos conhecimentos, o que não nos parece o caso. Categorizar, em si, a nós parece fazer parte de um processo de conceptualização maior, mais amplo, 
que envolve outros elementos e processos. Ao categorizarmos, favorecemos a inserção de conceitos em padrões, o que de fato os transporta a outro nível de conceptualização, inclusive porque a percepção de um dado conceito como pertencente a uma categoria é parte do seu entendimento. Em outras palavras: categorizar é padronizar, mas não é aprender, porque a ação de padronizar não implica necessariamente a formação de novos conceitos.

Dessa forma, o trabalho de Gentner \& Loewenstein descreve as evidências de que a pessoa aprendeu conceitos, mas não mostra especificamente como ela os aprendeu. Formar padrões é de fato uma ação cognitiva fundamental e importante e, nesse sentido, inserir um conceito numa categoria e formar novas categorias na mente é, de fato, um sinal de que se aprendeu um dado conceito. Assim, podemos pensar no processo de categorizar como um epifenômeno relacionado à projeção interdominial (Fauconnier, 1997), já que se apresenta como uma natural ação humana de organização de conceitos, a fim de favorecer a sua compreensão e o seu uso.

Desse modo, ainda estamos em busca de uma abordagem processual que permita refletir acerca do que ocorre cognitivamente à pessoa quando ela aprende, cria para si novos conceitos.

Tratemos agora do descolamento da realidade imediata e de como esse fenômeno tem sido normalmente tratado em estudos sobre aprendizado e formação de conceitos.

\section{Descolamento da realidade imediata}

$\mathrm{Na}$ relação entre aprendizado e consequente descolamento da chamada realidade imediata, a linguagem, por ser um sistema de instrumentos simbólicos, auxiliaria neste descolamento à medida que promovesse abstratização do pensamento. Tomandose, como diz Vygotsky, que o letramento só pode acontecer associado ao contexto em que se constrói e sendo partilhado com um grupo cultural, a pessoa internaliza conceitos do seu grupo imediato e depois descola-se deles.
Além da linguagem, a escolarização, ao trazer para o conhecimento da criança conceitos compartilhados por grupos sociais mais amplos e organizados, proporcionaria a ela, criança, ganhos cognitivos e capacidade de desligar-se do seu aqui e agora concreto, pessoal e prático e de alcançar o abstrato, geral e teórico. Nesse sentido, Vygotsky defende o desenvolvimento cognitivo como uma mudança qualitativa, por ser uma abstratização decorrente da entrada da pessoa em novos contextos sociais para além daquele onde nasceu.

Após a proposição dessas premissas, constituiuse, ao longo dos anos, a relação entre o afastamento da experiência imediata, tida como concreta, pessoal, prática e referencial, à experiência abstrata, geral, teórica (científica, portanto) e categorial proporcionada pela escola. Ainda se pode encontrar, entre as pesquisas que se dedicam a estudar a inteligência, a definição da capacidade de passar do concreto ao abstrato e do referencial ao categorial entre as evidências de desenvolvimento intelectual (Flynn, 2007).

Quanto a esse tópico, é importante verificar se de fato existem duas realidades, a imediata, da qual a pessoa deve desligar-se para alcançar a outra realidade,e a não imediata, na qual estão os conceitos escolarizados e científicos. Cabe também verificar se esses universos, em princípio sem relação entre si, contariam com a escola servindo de ponte entre eles e se seria possível à pessoa alcançar novos universos de experiência, por assim dizer, descolando-se dos que já conhece.

Normalmente, a descrição realizada pelos trabalhos que discutem o descolamento da realidade imediata também diz respeito a um universo de informações perceptuais, em contraposição às informações conceptuais pertencentes à realidade não imediata, tida como o universo descolado do empírico e no qual a pessoa se inseriria ao escolarizar-se. Isso nos leva naturalmente a compreender a conceptualização como uma ação mais organizada, mais teorizável, mais abstrata que a percepção, própria, por sua vez, das sensações imediatas, pessoais e não abstratizáveis. Assim, reconhecer esses dois universos implica reconhecer também uma dissociação entre percepção e conceptualização. Essa 
postulação está presente em trabalhos como Gentner \& Loewenstein (2002), descrito antes, e é considerado em Oliveira (1999), em que se evidencia que a ideia de descolamento da realidade imediata é um insight interessante para a localização epistêmica dos saberes acumulados pela pessoa, já que, por esse ponto de vista, é possível detectar diferenças entre conceitos e saberes relativamente aos universos de experiências de que eles fazem parte. A questão é que essas diferenças não são qualitativas.

Oliveira (1999) se propôs a verificar, com adultos de diferentes níveis de instrução, as relações entre escolaridade e modos de pensamento, estes entendidos como mais ou menos descolados da realidade imediata. É de se notar em seu trabalho a ideia de que a própria percepção da existência de uma realidade imediata e contextualizada, à qual estão atreladas pessoas de menor escolaridade, e a proposta de que a escolarização promoveria uma cognição mais independente do universo imediato da pessoa, não resistem a estudos que questionam o papel da escola como promotora desse tipo de desenvolvimento.

Em uma pesquisa baseada em opiniões sobre as diferenças entre os seres humanos e os outros animais, a hipótese de Oliveira partiu da concepção de que o modo de pensamento dependente de fatores da realidade imediata (e também mais fragmentado e com menos apoio metacognitivo) seria característico de pessoas com menos escolarização - no caso da pesquisa de Oliveira, adultos em classe de alfabetização. Já o modo de pensamento descontextualizado (e também mais teórico e com mais apoio metacognitivo) seria detectável em pessoas com mais escolaridade - na pesquisa da autora, estudantes universitários.

Os resultados da pesquisa revelaram, porém, pessoas adultas em processo de alfabetização plenamente capazes de pensar teoricamente sobre a questão posta: embora muitas respostas partissem do universo rural de onde provinha boa parte dos alunos, o tratamento dado aos animais em muitos casos era categorial - em contraponto à ideia do pensamento referencial, característico, segundo Flynn (2007), de menor desenvolvimento cognitivo, teórico e não aderido à sua realidade imediata. Esses dados revelam uma não-homonegeidade das formulações dos alunos de alfabetização no que tange à crença de que o seu pensamento está aderido à realidade imediata.

Quanto aos alunos universitários, alguns também responderam à questão posta tomando como exemplo animais próximos de sua realidade cotidiana, mas, diferentemente de muitos alunos de alfabetização, trataram-nos em nível individualizado, referencial, em geral citando seus animais de estimação. Outro fato interessante notado por Oliveira foi a inserção das respostas dos alunos universitários em padrões estruturais-didáticos de exposição de conteúdos, esperados em tarefas escolares: listas, tabelas, esquemas.

$\mathrm{Na}$ comparação entre as respostas dos alunos em alfabetização e as dos universitários, o parâmetro apontado por Oliveira foi uma organização definida não quanto ao seu conteúdo, já que tanto os alfabetizandos quanto os universitários ofereceram respostas relacionadas a ambos os modos de pensamento, mas sim quanto à sua forma de apresentação, já que a maioria das respostas dos alunos universitários se encaixava, nos termos do que Oliveira denominou modalidade de interação, na formatação escolar de apresentação de informações. Esses dados revelam um fator importante no processo de escolarização, que diz respeito ao fato de os conteúdos passarem a ser expressos dentro de determinados formatos, padrões de validação que os definem como escolares, e não pertencentes a outro universo. Ora, já se sabe que faz parte do aprendizado na escola não apenas assimilar um conceito; talvez tão importante quanto isso ou até, em muitos casos, mais importante, é assimilar as condições discursivas que o validam como conceito aprendido na escola e conferem à pessoa que o expressa o status de indivíduo letrado, instruído (Kleiman, 1998; Signorini, 2001).

Os dados analisados por Oliveira permitem concluir que não há modos de organização conceitual específicos para cada nível de escolarização; entre esses modos, o pensamento mais ou menos descolado da realidade imediata não parece ser parâmetro de desenvolvimento cognitivo. Para além do que foi 
concluído por Oliveira, estamos definindo neste texto que sequer existe a possibilidade de pensar apenas de uma ou de outra forma.

Em cotejo com a visão do aprendizado e do desenvolvimento cognitivo relacionado ao descolamento da realidade imediata e do movimento do perceptual em direção ao conceptual, coloca-se a postulação realista-experiencial (principalmente Lakoff \& Johnson, 1999 e Marmaridou, 2000) das bases corporificadas para a construção e compreensão de toda forma de significado. Muito embora hoje se questione a hipótese forte de Lakoff \& Johnson (por exemplo, na Cognitive Linguistics v. 3, n. 13), não se negam as bases perceptuais necessárias e sempre presentes, em que, além dos esquemas imagéticos (Johnson, 1987) e das dinâmicas de forças (Talmy, 2000) postos como bases de conhecimento para o aprendizado, leva-se em conta também a experiência da pessoa com os objetos à sua volta. Considera-se também o fato de não ser o corpo humano a fonte principal de acesso à construção de conceitos: entra aí também o mundo como espaço físico e os seus componentes e fenômenos, como a gravidade, a superfície, os percursos, as dimensões escalares etc. e o mundo como espaço cultural (Sinha \& Jensen de López, 2000).

Outro fato que também não se nega em relação a essas bases corporificadas é que elas nada têm de assistemáticas, ao contrário, trata-se aqui também de abstrações altamente estruturadas com base nas experiências que as pessoas têm, desde a mais tenra idade, com o espaço à sua volta - noções de direção, contenção, limite, verticalidade/horizontalidade etc., comprimidas em esquemas básicos de compreensão de noções de espaço/tempo, e noções lógicas, éticas, estéticas etc. (Johnson, 1987). Nesse sentido, em termos não objetivistas e experienciais, pode-se dizer que a realidade imediata, perceptual, está presente em tudo que pensamos, categorizamos e avaliamos. Nunca nos descolamos dela.

Já se viu neste texto que a tese da corporificação defendida pelo realismo experiencial dá conta de explicar grande parte do processo de significação, mas não ele todo. Deve-se levar em conta também que o conhecimento adquirido sobre um objeto inclui, entre as suas finalidades, seu uso normativo-social, ou seja, seu valor agregado no(s) ambiente(s) em que ele pode existir - ou seja, os artefatos que utilizamos não são culturalmente neutros: suas propriedades como bens coletivos lhes são intrínsecas, e os esquemas culturais que validam o seu uso estão representados na identificação que lhes atribuímos (Sinha \& Jensen de López, 2000). Esses posicionamentos levam à proposta de não haver uma distinção dicotômica entre percepção e conceptualização, já que só podemos realmente perceber as coisas através do que compreendemos, isto é, do que conceptualizamos. ${ }^{2}$

Com as bases culturais, reconhece-se, na companhia dos autores mais representativos do modelo usage-based para o estudo da construção dos significados de qualquer natureza (Tomasello, 1999, 2003; Marmaridou, 2000; Sinha \& Jensen de López, 2000; Fauconnier \& Turner, 2002; e outros mais), que a cognição por excelência é situada. Reconhece-se também a interpretação dada por Tomasello \& Rakoczy (2003) para a Teoria da Mente, segundo a qual a pessoa, para reconhecer os objetos, fatos e discursos à sua volta, deve conceptualizar simultaneamente as coisas em sua ontologia e em suas condições de validação - quer dizer, se elas são (e em que medida são) verdadeiras ou falsas. ${ }^{3}$ A postulação de Tomasello e Rakoczy permite-nos definir que a pessoa, além de reconhecer a dimensão experiencial e cultural de conceptualização para dar conta da compreensão das coisas, deve igualmente reconhecer a sua dimensão epistêmica, sem a qual também não poderá identificar e compreender os objetos físicos ou simbólicos apresentados pelas pessoas com quem interage. Em outras palavras: para formarmos

${ }^{2}$ É preciso registrar que, com a noção de interaction with knowledge and perception, McClelland \& Rumelhart (1981, p. 375) lançaram as bases para que se rompesse, posteriormente, a dicotomização entre percepção e conceptualização, ideia desenvolvida em Sinha \& Jensen de López (2000).

${ }^{3}$ Isso emerge em torno dos quatro anos de idade (Tomasello \& Rakoczy, 2003). 
conceitos, precisamos reconhecer os espaços mentais, contextuais, culturais e epistêmicos que ancoram toda forma de conceptualização, esteja ela atrelada ao cotidiano, seja ela tida como científica.

A ideia de que existem diferentes realidades a imediata, domínio do perceptual e concreto e a não-imediata, domínio do conceptual e do abstrato também é própria de algumas orientações modularistas de estudo da mente (Siegel, 1999, p. 164), segundo as quais os diferentes domínios de experiência interagem, mas um não estrutura o outro, no sentido que estamos definindo aqui - de que o perceptual estrutura o conceptual e vice-versa (Sinha, 1999a). O máximo que se tem é a transmissão de informações de um módulo a outro, mas não se assume uma perspectiva estruturadora, de mão dupla, entre eles.

Dessa forma, pelo que se expôs aqui, o descolamento da realidade imediata também é um epifenômeno de acontecimentos mais fundamentais que se dão na mente humana: a pessoa reconhecer novas dimensões de realidade e, por isso, as condições de validação dos conceitos nela inseridos. Nesse sentido, o descolamento é aparente, porque as bases esquemático-espaciais, culturais e epistêmicas de conhecimento estão sempre presentes, alicerçando a compreensão.

Diante do que está dito, podemos afirmar que, assim como não saímos do perceptual, do imediato, também nunca saímos do conceptual, do abstrato, haja vista o fato de que as compreensões de experiência espacial, as mais básicas que temos, constroem-se em nossa mente como abstrações. Além disso, não há em nossa ontogenia um período em que vivemos um universo apenas perceptual ou conceptual. Percepção e conceptualização, concreto e abstrato, imediato e não imediato interagem ininterruptamente na formação de toda representação mental de que nossa cognição é capaz.

Assim, podemos afirmar que a pessoa que cogniza requer em todo momento o acesso à realidade imediata e que não há diferença de qualidade entre aquilo que se aprende e o que ainda não se sabe; todos os conceitos que o ser humano utiliza são artefatos semióticos, independentemente da sua natureza ou origem. En- tretanto, de fato ocorre uma movimentação cognitiva entre diferentes domínios de experiências, já que o ser humano é capaz de reconhecer as novas realidades que tem diante de si. Mas isso é efeito da propriedade cognitiva humana de integrar conceitos, como veremos na próxima seção.

\section{Como as pessoas adquirem conceitos - o aprendizado como double-scope blending}

Ao longo deste artigo, temos visto que as duas propostas principais de discussão sobre o aprendizado como processo - a articulação de conceitos e o descolamento da realidade imediata - não lograram responder à pergunta de Vygotsky de como os conceitos são formados; apenas apontaram o que acontece, em termos de ações cognitivas, depois que esses conceitos são formados: como os manipulamos, relacionamos e enquadramos. A rigor, essas discussões acerca do aprendizado não abarcam a consideração processual de como ele acontece, quer dizer, de como e com que instrumentos a mente opera para construí-lo.

Qualquer que seja o modelo processual proposto, ele deverá reconhecer a relação de mão dupla entre a pessoa que cogniza e o universo à sua volta, num fluxo contínuo de informação em ambos os sentidos, e não supor que o ser humano apenas recebe passivamente as informações, sem atuar sobre a construção do significado. A psicolinguística experimental, por exemplo, já tem há muito assumido essa condição do processamento de informação e verificado suas evidências. Sobre isso, é importante citar a formulação do interactive activation model (McClelland \& Rumelhart, 1981; Rumelhart \& McClelland, 1982), que, definido primeiramente como um modelo de percepção das palavras durante a leitura, propõe o direcionamento simultâneo top-down e bottom-up de processamento cognitivo, que busca traduzir a interação entre a pessoa que cogniza e o contexto espaço-temporal onde está o objeto cognoscível.

O chamado modelo interativo-top-down/bottomup - traz vantagens em relação às ideias de articulação de conceitos e descolamento da realidade imediata, 
porque captura processualmente a relação necessária que há entre as estruturas prévias que a pessoa precisa já ter em mente (Resnick, 1994) e as novas informações com as quais está interagindo. Mas a sua adoção não é suficiente para que possamos defini-lo como base processual do aprendizado em termos cognitivos, porque, restrito à movimentação de informações entre a mente e o contexto, esse modelo não dá conta de incluir - quanto mais de definir como se constitui e do que se constitui - o estatuto do novo conceito formulado pela mente e de como ele se relaciona com os conceitos que servem de input para a sua formação, para que se atrelem, em um só esquema estrutural, fontes, processo e resultado.

O modelo descritivo apropriado a essas necessidades seria uma representação esquemática unificada referente à construção processual dos significados e dos conceitos, dando conta de como ela acontece e no momento em que ela acontece. Nesse sentido, a ideia de aprender necessariamente passa pela exploração das bases de conhecimento já citadas neste artigo e pelo intercurso de um saber processual, que permite lançarmos mão de saberes já existentes para a formulação de outros e novos saberes.

Com base na proposta do processamento interativo, uma das definições interessantes, aplicada à cognição em geral, é, entre outros achados, o fato de que qualquer nova informação só é formulada pela mente depois que esta o avalia, analisa e relaciona aos saberes já adquiridos, o que é um processo de estruturação - especificamente, de integração conceptual (Fauconnier \& Turner, 2002, principalmente), uma capacidade inata ao Homo sapiens.

Levando em conta as bases metodológicas de uma ciência da cognição não objetivista e não autonomista (Fauconnier, 1999), não se postulam aqui diferentes processos cognitivos responsáveis pelo aprendizado, mas sim uma rede processual responsável pelo padrão geral de integração conceptual, ampla o suficiente para abarcar as funções psíquicas superiores definidas por Vygotsky: a Rede de Integração Conceptual (RIC). Assumir a formação de conceitos pela via da RIC permite referendar a premissa deste artigo de que, para aprender, a pessoa procede sempre a uma mesma sistematização, independentemente do tipo de conceito.

Fauconnier \& Turner definem a RIC como uma singularidade processual que agrega todos os feitos da mente humana - a linguagem, a sociedade, a ciência, a religião, a arte. $\mathrm{O}$ que torna possível aos autores afirmar isso é que, embora eles em princípio estejam interessados na construção do significado linguístico, reconhecem, em contraposição às abordagens modularistas de estudo da cognição humana, que a forma como aprendemos a linguagem não é exclusiva à linguagem.

Tomando como base as postulações de Fauconnier $\&$ Turner, o que estamos propondo neste artigo é que faz parte da RIC, como uma singularidade, aquilo que a literatura aqui tratada chama de formação de novos conceitos, ou seja, o aprendizado, justamente aquele breve momento em que nos damos conta de que aprendemos alguma coisa, junto com todas as ações que vêm em decorrência - a categorização, a articulação de conceitos, a sua utilização em outros domínios -, procedimentos que, em termos gerais, também se incluem na RIC. Com base nisso, podemos postular que a forma como aprendemos não é específica em nada, mas sim é parte de uma habilidade geral, subjacente e única a todas as formas de conceptualização por parte da mente humana: uma "habilidade de juntar duas coisas" (Fauconnier \& Turner, 2008), para formar uma terceira.

Nesse sentido, para uma abordagem processual da ação cognitiva de aprender, tem-se a integração conceptual como operação cognitiva global (Fauconnier \& Turner, 2002). A sua dinâmica compõe-se da articulação de dois espaços input associados com base no que têm em comum, num espaço genérico, e da projeção seletiva dos elementos dos inputs para formação de um quarto espaço, denominado espaçomescla, que é autônomo em relação aos inputs e traz elementos a ele específicos.

O esquema de mesclagem proposto por Fauconnier \& Turner (2002, p. 46) apresenta-se da seguinte forma: 
Figura 1 - Esquema básico de integração conceptual

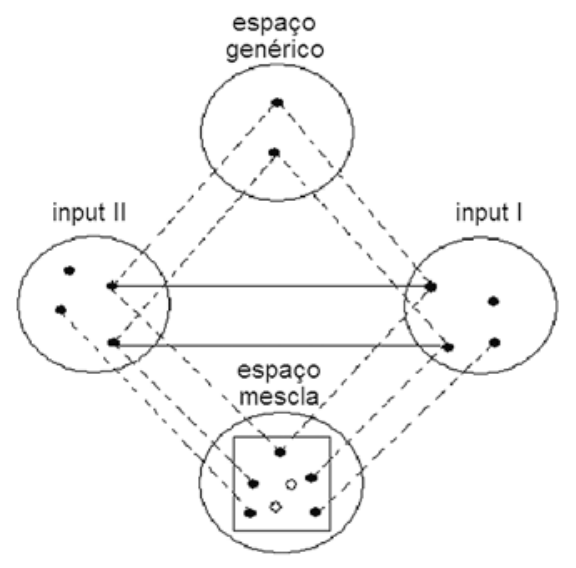

Os participantes do processo de construção de significados proporcionado pela mesclagem conceptual - no nosso caso, conceitos-base para a formação de outros novos conceitos na escola - estão em diferentes domínios de experiência: no input I, o domínio dos conhecimentos do aluno; no input II, o domínio dos conhecimentos da escola. Os domínios input encontram-se numa situação de fluxo, de troca; para usar a terminologia clássica do processamento interativo, trata-se dos movimentos top-down e bottom-up, respectivamente. Isso nos permite dizer que o modelo interativo proposto por Rumelhart \& McClelland (1982) faz parte de um universo processual mais amplo, de integração conceptual.

Esse processo apresenta ainda a vantagem de incluir outro importante movimento presente na formação de novos conceitos: a vinculação dos input a um espaço genérico, fonte das associações entre eles e da possibilidade de se mesclarem. Soma-se a isso a resultante do processo, ou seja, o novo conceito, com base na articulação de dados (não todos) dos inputs, mas também possuindo traços que lhe são próprios e não abstraíveis dos inputs. O caráter autônomo do conceito aprendido confere-lhe a propriedade de estar numa estrutura emergente, garantindo a sua identificação como o espaço em que se formatam os conceitos aprendidos, já que estes se relacionam aos que os motivaram mas trazem por si atributos novos que os individualizam. Outro fator que manifesta a autonomia do conceito no espaço emergente está representado nos círculos brancos no espaço: trata-se de aspectos que, por não pertencerem a qualquer dos inputs, conferem-lhe caráter independente em relação aos espaços nos quais se origina.

Observa-se também que o esquema da integração conceptual evidencia a liberdade de identificação de contrapartes de um mesmo referente em diferentes domínios-input (representadas nas linhas cheias), da conexão entre referentes (representada nas linhas tracejadas) e da seleção de elementos para a construção do espaço emergente. Essas características garantem a natureza absolutamente pessoal da formação dos conceitos nos espaços emergentes, ou seja, do aprendizado, por parte da pessoa que cogniza.

Para uma melhor compreensão da natureza da integração conceptual, é importante relatar que, no trabalho de identificação dos saberes processuais fundamentais, Fauconnier \& Turner (1996), motivados inicialmente a oferecer um desenvolvimento da teoria da metáfora, propuseram o modelo de mesclagem como um processo de quatro domínios, a fim de acomodar esquemas inferenciais mais ricos. $\mathrm{Na}$ investigação sobre a mesclagem, Fauconnier \& Turner detectaram uma uniformidade estrutural subjacente a todos os processos mentais que, ao longo da história da ciência e da filosofia, têm sido identificados: metáforas e analogias em geral, framing, acesso a contrafactuais, aquisição da gramática etc. Posteriormente, outros exemplos mostraram que a metáfora era apenas um dos muitos fenômenos cognitivos que envolvem a mesclagem.

Do trabalho de Fauconnier \& Turner proveio o diagrama básico apresentado anteriormente, que compreende o que os autores denominam integration network, um contínuo de processos cognitivos que partem da formação básica descrita e que inclui variadas ações cognitivas: além da metáfora, a metonímia (Fauconnier, 1985); a formação dos contrafactuais e a correlação (Fauconnier, 1997); o reenquadre de cena (Coulson, 2001) às ações metacognitivas; a percepção visual e auditiva; a formação das imagens dos participantes numa interação (Salomão, 2003); as construções culturais; as descobertas científicas; 
o raciocínio matemático e muitas outras atribuições, dentre elas o aprendizado.

Dado o caráter múltiplo dos fenômenos cognitivos, estamos todo o tempo lidando simultaneamente com diferentes processos relacionados à RIC, como o que Gentner \& Loewenstein (2002) descreveram como sendo as possíveis ações de aquisição de conceitos: a definição de padrões necessária à existência dos inputs e do espaço genérico; as projeções inferenciais como relações de correlação entre os inputs; a alteração representacional que ocorre no espaço-mescla. É possível estabelecer essa relação porque a construção cognitiva requer variadas formas de integração conceptual, separadas no tempo por milésimos de segundo. Mas a categorização isoladamente não traz as mesmas características da RIC, porque seus elementos não se prestam a inputs que se organizam mediante um espaço genérico, tampouco geram conceitos autônomos em espaços-mescla.

Dessa forma, não é fato inédito acrescentarmos que $\mathrm{o}$ ato de aprender, criar um novo conceito, faz parte do universo da integração conceptual. O que este artigo propõe é o fato de que, por envolver dois domínios de realidade distintos - como já vimos, o domínio de conhecimento da pessoa e o domínio contextual -, a forma de integração conceptual reconhecível como base do aprendizado encaixa-se no que Fauconnier \& Turner denominam double-scope blending, que vem a ser o processo de

\footnotetext{
[...] integrar dois ou mais arranjos conceptuais como input cujas estruturas tipicamente conflitam de forma radical em termos de relações conceptuais vitais, tais como causaefeito, modalidade. Estrutura de participantes, papel-valor etc., em um novo arranjo conceptual cuja estrutura se delineia seletivamente a partir das estruturas dos inputs, e desenvolve estruturas emergentes não encontradas em nenhum dos inputs". (2009, tradução minha)
}

Dessa forma, pode-se descrever o momento do aprendizado na escola como a formação de um espaço emergente onde se localiza o novo conceito, diante de um universo processual em que se relacionam dois espaços constituídos de diferentes relações vitais: de um lado, o espaço de realidade do aluno; de outro, o espaço de realidade da escola.

O modelo do double-scope blending dá conta da natureza descontínua do aprendizado como processo cognitivo porque mostra como é possível à pessoa lidar com elementos de diferentes domínios de realidade para criar novos conteúdos. Esse fator alia-se à propriedade de a projeção interdominial ser seletiva (Lakoff \& Johnson, 1980): no espaço input não é necessário haver todos os elementos que em princípio fariam parte de um conceito ou uma experiência. Assim, a pessoa, no ato de aprender, ao abstrair do conceito apenas o que lhe interessa naquele momento, comprimiria (termo de Fauconnier \& Turner, 2008) as estruturas conceptuais dos inputs, redimensionando os conceitos-base para um tamanho compatível com as necessidades cognitivas do momento, para, na construção do espaço emergente, locus do novo conceito por ela elaborado, compor um arranjo entre os elementos dos inputs que lhe interessa selecionar e os elementos inerentes ao espaço emergente. Faz isso para criar novos saberes que são construídos por ela e apenas por ela, o que torna o instante do aprendizado um momento único, inalienável e intransferível.

Discutir o processo do aprendizado em termos de integração conceptual apresenta a vantagem de permitir justamente realizar a ideia posta por Vygotsky e já enunciada neste artigo: reconhecer uma base conceptual dinâmica e unificada para criação de todo e qualquer conceito por parte da pessoa, diferentemente de, na suposição de que existe um conjunto de processos responsável por isso (proposta de Bergen \& Feldman, 2006), haver a necessidade de perscrutar qual processo se relacionaria a qual conceito.

No caso específico do processo de double-scope blending no âmbito escolar, o aluno, para aprender os conteúdos na escola, precisa comprimir elementos de dois diferentes domínios de realidade, o das experiências escolares e o das experiências cotidianas, para mesclar seus elementos e conceptualizar novos conteúdos, numa ação absolutamente individual. O trato com duas dimensões de realidade é inerente 
ao aprendizado, já que para isso a pessoa tem de encontrar as dimensões do conhecimento que ela traz, num movimento top-down, e o conhecimento escolar materializado no espaço da sala de aula, num movimento bottom-up .

A descrição posta aqui permite postular que a base do aprendizado está na integração de universos cujos componentes se movimentam ascendente e descendentemente e em conjunto, mas esse movimento é parte de algo maior, porque é preciso dar conta do que justifica que esses universos estejam relacionados, e reconhecer como o novo conceito é gerado com base neles. A geração de um novo conceito é possibilitada pela compressão desses universos e pela seleção de elementos de cada um nos espaços input.

\section{Pensando na escola}

Pelo que se postulou neste artigo, nota-se que, para haver integração conceptual, é necessário estarem nítidos na mente da pessoa os universos de experiência que servirão de input para a mesclagem, porque apenas se eles forem completamente visualizados é que poderão ser capturados e associados em relação ao que têm em comum.

Sabemos, quanto a isso, que a double-scope blending requer o acesso a pelo menos dois universos de experiências, mas os saberes empregados nelas pertencem cada um ao seu universo específico, cujo conhecimento prévio é necessário para haver mesclagem e formação de novos conceitos. Portanto, o processo específico de double-scope blending que envolve como input os universos de experiência cotidiana e escolar necessariamente implica o movimento de um universo ao outro, o que significa dizer que, na elaboração de novos conceitos, o aluno em dado momento sai da realidade de sua vida cotidiana, mas foi visto aqui que isso não significa descolar-se dela, porque as bases para a compreensão tanto de uma realidade quanto de outra são as mesmas. Nesse enquadramento, a questão de o conteúdo a ser ministrado na escola estar próximo ou distante do universo imediato do aprendiz é reconfigurada em função de ele, no exercício do aprendizado, reconhecer como real, ou seja, validar em sua mente, os domínios de experiências em que os conteúdos tomam lugar.

Essa proposta traz implicada a percepção de que aprender, entre muitas outras propriedades, é também reconhecer as realidades que enquadram e validam esses conteúdos para que eles sejam compreendidos como conceitos. Ou seja, para reconhecer os objetos de conhecimento na escola como instrumentos de aprendizado o aluno precisa reconhecer os lugares de onde eles vêm. Então, se a escola não se faz como realidade disponível ao aluno, e se ele mesmo assim conseguir dar-se conta dos objetos simbólicos ali dispostos, ele vai relacioná-los de outra forma com os instrumentos e conhecimentos de que dispõe.

Para evitar esse problema, a escola precisa apresentar-se à pessoa como uma realidade a ser construída com base em outras que ela já conhece, mas de forma não alijada da chamada realidade imediata do aluno, porque ambas precisam ser percebidas e conceptualizadas por ele. Apenas oferecendo-se a ele a possibilidade desse relacionamento é que se pode definir fidedignamente quão importante é para o ser humano estar na escola, aprender a ler e escrever, assimilar os conceitos lá transmitidos, associar as habilidades necessárias à sua compreensão às habilidades e compreensões com as quais lida fora da escola. Toda informação nova a que a pessoa tem acesso e todo aprendizado trazem em sua essência a possibilidade de construção de novas categorias e a detecção de planos de realidade em que elas podem estar presentes e validadas. Cabe à escola favorecer ao aluno a abertura dos caminhos que ele pode percorrer para alcançar e visualizar novos espaços para cognizar. Esse favorecimento só se possibilita com a instauração do que Tomasello (1999) denomina cena de atenção conjunta, que, no caso da interação em sala de aula, possibilita-se no olhar que o professor, como falante primário, dirige ao seu aluno.

Ora, já se atestou mais de uma vez a dificuldade de a escola, em especial a escola pública de países emergentes como o Brasil, reconhecer a realidade em que se encontram os alunos; o que se verifica a rigor é o trato único e restrito aos conhecimentos validados 
pela instituição escolar. Os termos dessa validação são regularizados e instituídos por meio de práticas discursivas de diferentes naturezas, que não apenas dizem respeito ao feitio dos conceitos e à forma como eles serão considerados como aprendidos, mas também definem como se configurarão "a produção das identidades das professoras", "suas formas de enxergar a sala de aula, os alunos, a educação" (Sommer, 2007, p. 58). Em outras palavras, o estabelecimento de quais conceitos são merecedores de aprendizado na escola está inserido num universo de práticas escolares que orientam nossa observação de todos os referenciais pertinentes ao universo escolar: como serão vistos, que valor terão, o que eles representam no universo fora da escola, que status conferirão aos alunos que os possuírem.

Inclui-se na composição dessa prática discursiva o fato de a escola ainda focalizar as experiências que os alunos ainda não acumularam, o que lhes dificulta observar os saberes que já adquiriram. Tal cenário não permite aos alunos estabelecer pontes entre os conteúdos escolares, de um lado, e cotidianos, de outro. Nesse contexto, não é possível favorecer a double-scope blending em sala de aula; portanto, não se favorecerá a formação de novos conceitos, ou seja, o aprendizado.

Para haver sucesso na práxis escolar que se propõe a estimular o aluno a mesclar os conteúdos da sua realidade aos da escola, é preciso observar que as práticas de letramento são não apenas dependentes das comunidades em que elas são adquiridas, mas dependem também dos modelos interacionais e padrões idealizados de conhecimento em que as ações de leitura e escrita normalmente se dão (Kleiman, 1998, p. 197), ou seja, nas molduras comunicativas a elas relacionadas. Por esse motivo, o reconhecimento do espaço escolar como um espaço distinto do espaço da sua casa, do seu ambiente com os amigos etc., em que os objetos são diferentes e as suas formas de observação também, ${ }^{4}$ é fundamental ao aprendiz

\footnotetext{
${ }^{4}$ Como já apontado em trabalhos de análise crítica do discurso (Street, 1984, e Kleiman, 1998, por exemplo).
}

para que ele conceptualize os conceitos segundo a sua validação num dado contexto. Para esse fim, defende-se um ensino que reconheça capacidades e conhecimentos que os alunos já trazem, para que eles sejam expandidos, em vez de operar sobre aquilo que eles não sabem. Aliás, frequentemente tais deficiências lhes são apontadas, o que lhes diminui a autoestima, prejudica sua autoimagem e lhes dificulta novos aprendizados. Sem esse reconhecimento, a escola nunca será para eles um lugar definido, específico, e assim, muito provavelmente, eles jamais descobrirão e experimentarão o impacto e o enriquecimento que aprender a ler, a escrever, a compreender os conceitos escolares podem representar na sua vida.

O caminho para essa descoberta é surpreendentemente fácil e acessível aos agentes escolares. Basta que eles passem a enfatizar o que os alunos já trazem como conhecimento adquirido, e não o conhecimento que lhes falta. $\mathrm{E}$, de fato, o relato de muitos professores que fizeram essa opção e que puderam experimentar, com seus alunos, reais e prazerosos momentos de aprendizado apenas comprova isso. A possibilidade de expansão de conhecimentos de universos conhecidos para os não conhecidos gerada por essa práxis comprova a hipótese de Vygotsky citada no início deste artigo, de que o desenvolvimento cognitivo tem natureza expansional. Expansão essa favorecida pela autoconfiança decorrente da valorização do que a criança sabe, o que a torna corajosa para explorar o que não sabe.

A importância do estímulo para que o aluno alcance o agenciamento do seu próprio aprendizado é justificada e autenticada pela hipótese da RIC, mas encontra também forte anteparo nas hipóteses postas por Vygotsky sobre o desenvolvimento cognitivo, em especial na postulação da zona de desenvolvimento proximal, lugar necessário para a efetivação da double-scope blending escolar. Nesse sentido, ao podermos dialogar com a questão do autor russo acerca de como o aprendizado se faz como processo cognitivo, verificamos que a ciência da cognição traz, para os estudos sobre educação, a comprovação de que ainda se mantém como base sólida o que Vygotsky, no 
início do século passado, formulou a respeito de como o aprendizado - como ação conjunta, como produto de estímulo para aprimorar mais ainda o que a pessoa já traz de bom - pode desenvolver a mente e melhorar a vida das pessoas.

\section{Referências bibliográficas}

BERGEN, Benjamin; FELDMAN, Jerry. It's the body, stupid: concept of learning according to cognitive science. ICSI Technical report, 2006. Disponível em: <http://www.icsi.berkeley.edu/pubs/ techreports/tr-06-002.pdf>. Acesso em: 2 mar. 2009.

CLARK, Eve. How language acquisition builds on cognitive development. Trends in Cognitive Sciences, v.8, n. 10, p. 472-478 out. 2004.

COULSON, Seana. Semantic leaps: frame shifting and conceptual blending in meaning cosntruction. Cambridge: University Press, 2001.

DELEUZE, Gilles; GUATTARI, Félix. O que é filosofia? São Paulo: Editora 34, 1992.

FAUCONNIER, Gilles. Mental spaces. Cambridge: University Press, 1985.

. Mappings in thought and language. Cambridge:

University Press, 1997.

Methods and generalizations. In: JANSSEN, T., REDEKER, G. (Orgs). Cognitive Linguistics: foundations, scope and methodology. Berlin/New York: Mouton de Gruyter, 1999. p. 95-127.

FAUCONNIER, Giles; TURNER, Mark. Blending as a central process of grammar. In: GOLDBERG, Adele. (Org.). Conceptual structure, discourse and language. Stanford: CSLI, 1996. p. 113-130.

The way we think: conceptual blending and the mind's hidden complexities. New York: Basic Books, 2002.

The origin of language as a product of the evolution of double-scope blending. Behavioral and brain sciences, v.31, p. 520-521, out. 2008 .

. The origin of language as a product of the evolution of modern cognition. In: LAKS, Bernard et al. (Orgs.). Origin and Evolution of Languages: approaches, models, paradigms. London: Equinox, 2009. p. 141-178.

FILLMORE, Charles. Topics in lexical semantics. In: COLE, R. (Org.). Current issues in linguistic theory. Bloomington: Indiana University Press, 1977. p. 76-138.

FLYNN, James Robert. What is intelligence: beyond the Flynn effect. Cambridge: University Press, 2007.
GENTNER, Dedre; LOEWENSTEIN, Jeffrey. Relational language and relational thought. In: AMSEL, Eric; BYRNES, James P. (Orgs.). Language, literacy and cognitive development. London: Lawrence Erlbaum, 2002. p. 87-119.

GOFFMAN, Erwin. Frame analysis. Boston: Northeastern University Press, 1986.

JOHNSON, Mark. The body in the mind: the bodily basis of meaning, imagination, and reason. Chicago: University Press, 1987.

KARMILOFF-SMITH, Annette. Beyond modularity: a developmental perspective on cognitive science. Cambridge: The MIT Press, 1992.

KLEIMAN, Angela. Schooling literacy and social change: elements for a critical approach do the study of literacy. In: OLIVEIRA, Marta Kohl de; VALSINER, Jean (Orgs.). Literacy in human development. Stanford: Ablex Publishing Corporation, 1998. p. $183-225$.

KUNDA, Ziva. Social cognition: making sense of people. Cambridge: The MIT Press, 1999.

LAKOFF, George. Women, fire and dangerous things: what categories reveal about the mind. Chicago: University Press, 1987.

LAKOFF, George; JOHNSON, Mark. Metaphors we live by. Chicago: University Press, 1980.

Philosophy in the flesh: the embodied mind and its challenge to western thought. New York: Basic Books, 1999.

MARMARIDOU, Sophia. Pragmatic meaning and cognition. Amsterdam/Philadelphia: John Benjamins, 2000.

MCCLELLAND, James; RUMELHART, David. An interactive activation model of context effects in letter perception: Part 1: an account of basic findings. Psychological Review, v. 88, n. 5, p. $375-407$, set. 1981 .

OLIVEIRA, Marta Kohl de. Organização conceptual e escolarização. In: OLIVEIRA, Marcos B. de; OLIVEIRA, Marta Kohl de (Orgs.). Investigações cognitivas: conceitos, linguagem e cultura. Porto Alegre: Artmed, 1999. p. 81-99.

OLSON, David. What writing does to the mind. In: AMSEL, Eric; BYRNES, James (Orgs.). Language, literacy and cognitive development. London: Lawrence Erlbaum, 2002. p. 153-165.

OLSON, David; ASTINGTON, Janet. Wilde. Talking about text: how literacy contributes to thought. Journal of Pragmatics, v. 14, n. 5, p. 705-721, out. 1990 .

RESNICK, Lauren. Situated rationalism: biological and social preparation for learning. In: HIRSCHFELD, Lawrence; GELMAN, Susan (Orgs.). Mapping the mind: domain specificity in cognition 
and culture. Cambridge: University Press, 1994. p. 474-493. ROSCH, Eleanor. Principles of categorization. In: ROSCH, Eleanor; LLOYD Barbara (Orgs.). Cognition and categorization. Hillsdale: Lawrence Erlbaum, 1978. p. 28-46.

RUMELHART, David; McCLELLAND, James. An interactive activation model of context effects in letter perception: part 2 - The contextual enhancement effect and some tests and extensions of the model. Psychological Review, v. 89, n. 1, p. 60-94, 1982.

SALOMÃO, Maria Margarida Martins. Razão, realismo e verdade: o que nos ensina o estudo sócio-cognitivo da referência. Cadernos de Estudos Lingüísticos, v. 44, n. 1, p. 71-84, jan./jun. 2003.

SIEGEL, Daniel. The developing mind: how relationships and the brain interact to shape who we are. New York: Guilford Press, 1999.

SIGNORINI, Inês. Literacy and communicative (in)flexibility: interactional failure in Brazilian programs of diffusion of knowledge. Journal of pragmatics, v. 33, p. 969-997, jul. 2001.

SINHA, Chris. Situated Selves: learning to be a learner. In: BLISS, Joan; SÃLJÕ, Roger; LIGHT, Paul (Orgs.). Learning Sites: Social and Technological Resources for Learning. Oxford: Pergamon, 1999a. p. 32-48.

Grounding, mapping and acts of meaning. In:

JANSSEN, T.; REDEKER, G. (Orgs.). Cognitive Linguistics: foundations, scope and methodology. Berlin \& New York: Mouton de Gruyter, 1999b. p. 223-255.

SINHA, Chris; JENSEN DE LÓPEZ, Kristine. Language, culture and the embodiment of spatial cognition. Cognitive Linguistics, v. 11, n. 1, p. 17-41, 2000.

SOMMER, Luís Henrique. A ordem do discurso escolar. Revista Brasileira de Educação, v. 12, n. 34, , p. 57-67, abr. 2007.

STREET, B. Literacy in theory and practice. Cambridge: University Press, 1984

SUSSWEIN, Noah; BIBOK, Maximilian B.; CARPENDALE, Jeremy. Reconceptualizing internalization. International Journal for Dialogical Science, v. 2, n. 1, p. 183-205, out. 2007.

TALMY, L. Towards a cognitive semantics. v. 1. Cambridge: The MIT Press, 2000.

TAYLOR, Taylor, J. Linguistic Categorization: prototypes in linguistic theory. Oxford: Clarendon Press, 1987.

TOMASELLO, Michael. Piagetian and Vygotskyan approaches to language acquisition. Human Development, v. 39, p. 269$276,1996$.

The Cultural origins of human cognition. Harvard: University Press, 1999.

The key is social cognition. In: GENTNER, Dedre; GOLDIN-MEADOW, Susan (Orgs.). Language in mind: advances in the study of language and thought. Cambridge: The MIT Press, 2003. p. 47-56.

Origins of human communication. Cambridge: The MIT Press, 2008.

TOMASELLO, Michael; RAKOCZY, Hannes. What makes human cognition unique? From individual to shared to collective intentionality. Mind and language, v. 18, n. 2, p. 121-147, abr. 2003.

VYGOTSKY, Lev (1998). Pensamento e linguagem. 2. ed. Tradução Jefferson Luiz Camargo. São Paulo: Martins Fontes, 1998.

WELLS, G. (1994). Learning and teaching "scientific concepts": Vygotsky's ideas revisited. Paper presented at the conference "Vygotsky and the human sciences", 1994. Disponível em: <http://people.ucsc.edu/ gwells/Files/Papers_Folder/ ScientificConcepts.pdf>. Acesso em: 1 fev. 2005.

ANA FLÁVIA LOPES MAGELA GERHARDT, doutora em letras vernáculas, língua portuguesa, pela Universidade Federal do Rio de Janeiro (UFRJ), é professora dessa universidade e pesquisadora em linguística sociocognitiva e ensino de língua materna. Publicações recentes: em co-autoria com Camila de Faro de Albuquerque \& Igor de Souza Silva, A cognição situada e o conhecimento prévio em leitura e ensino (Ciências e cognição, v. 14, n. 2, p. 74-91, jul. 2009); Teorias e conceitos em linguística cognitiva: (in)compreensões (Cadernos de Estudos Linguísticos, v. 45, p. 21-31, jul./dez. 2003); Uma visão sociocognitiva da avaliação em textos escolares (Educação e Sociedade, v. 27, n. 97, p. 1181-1203, set./dez. 2006). Pesquisa em andamento: "Processos cognitivos e leitura: atividades escolares em questão”.Email: gerhardt@ufrj.br

Recebido em março de 2009 Aprovado em fevereiro de 2010 
de Walter Benjamin, que retratam, de forma autobiográfica, o papel do jogo para a formação do self na infância.

Palavras-chave: Jogo, brincadeira, mimese, identidade, socialização, infância

Games, mimesis and childhood: the role of children's play in the development of self

This paper presents a sociological analysis of the influence of children's play on socialization processes and on the development of self in childhood, making use of classical authors like Walter Benjamin and George Herbert Mead and some of their contemporary interpreters like Gunter Gebauer and Christoph Wulf, all of whom organised this discussion around the concept of mimesis. In the second part, it analyses two "images" present in Childhood in Berlin around 1900, by Walter Benjamin, which portrays the role of children's play in the development of self in childhood from an autobiographical perspective.

Key words: play, game, mimesis, identity, socialization, childhood

Juego, mimesis e infancia: el papel de jugar en los procesos de construcción del self

El artículo aborda, desde una perspectiva sociológica, el papel del juego en los procesos de socialización infantil y de la formación del self en la infancia, recurriendo a autores clásicos como Walter Benjamin y Georg Herbert Meady de algunos de sus intérpretes contemporáneos, como Gunter Gebauer y Christoph Wulf, autores que organizaron esa discusión en torno del concepto de mimesis. Presenta también un análisis de dos "imágenes" presentes en La infancia en Berlín alrededor de 1900, de autoría de Walter Benjamin, que retratan de forma autobiográfica el papel del juego para la formación del self en la infancia.

Palabras clave: Juego, diversión, mimesis, identidad, socialización, infancia
Ana Flávia Lopes Magela Gerhardt

Integração conceptual, formação de conceitos e aprendizado

Com base nas premissas postas pelo psicólogo russo Lev Vygotsky acerca do desenvolvimento cognitivo, discutemse dois fatos geralmente apontados por pesquisas em educação que focalizam as formas de organização conceptual por parte dos alunos: a articulação de conceitos e o descolamento da realidade imediata, a fim de definir seu estatuto de epifenômenos decorrentes da aquisição de novos conceitos, dado que ambas as operações focalizam organizações de conceitos que resultam do processo do aprendizado, e não o que de fato ocorre na mente dos alunos no momento em que aprendem. Propõe-se assumir os pressupostos da psicologia cognitiva contemporânea que permitem reconhecer o momento de aprender como um processo de mesclagem ou integração conceptual ou, mais especificamente, doublescope blending, descrevendo as suas características particulares em relação ao trato com os conceitos em sala de aula, bem como aos participantes do processo de aprendizado na escola. Palavras-chave: psicologia cognitiva; integração conceptual; Lev Vygotsky; desenvolvimento cognitivo; escolarização; aprendizado

\section{Conceptual integration, concept formation and learning}

Based on the premises established by the Russian psychologist Lev Vygotsky concerning cognitive development, we discuss two facts generally indicated by educational research which focus on the forms of conceptual organization by students: the articulation of concepts and their detachment from immediate reality, in order to define their status as epiphenomena related to the acquisition of new concepts, since both cognitive operations focus on the organization of concepts which result from the process of learning, and not on what really happens in the students' minds at the moment they learn. We propose to take the assumptions of contemporary Cognitive Psychology that allow us to recognize the moment of learning as a process of mixing or conceptual integration or, more specifically, double-scope blending, describing its particular characteristics in relation to handling concepts in the classroom as well as to the participants of the learning process in school.

Key words: cognitive psychology; conceptual integration; Lev Vygotsky; cognitive development; schooling; learning

Integración conceptual, formación de conceptos y aprendizaje

A partir de las premisas puestas por el psicólogo ruso Lev Vygotsky a respecto del desarrollo cognitivo, se discuten dos hechos generalmente apuntados por encuestas en Educación que focalizan las formas de organización conceptual por parte de alumnos: la articulación de conceptos y la desunión de la realidad inmediata, con el fin de definir su estatuto de epifenómenos consecuentes de la adquisición de nuevos conceptos, dado que ambas operaciones enfocan organizaciones de conceptos que resultan del proceso del aprendizaje, y no lo que de hecho ocurre en la mente de los alumnos en el momento en que aprenden. Se propone asumir los preceptos de la Psicología Cognitiva contemporánea que permiten reconocer el momento de aprender como un proceso de mezcla o integración conceptual o, más especificamente, doublescope blending, describiendo sus características particulares en relación al tratamiento con los conceptos en clase, bien como a los participantes del proceso de aprendizaje en la escuela. Palabras clave: psicología cognitiva; integración conceptual; Lev Vygotsky; desarrollo cognitivo; escolaridad; aprendizaje 